\title{
Arteterapia y fonoaudiología en la potenciación de las habilidades comunicativas en jóvenes con discapacidad intelectual
}

\author{
Rocío MOLINA BEJAR ${ }^{1}$ \\ Universidad del Rosario \\ rocio.molina@urosario.edu.co \\ María Paula VARGAS MOSQUERA ${ }^{2}$ \\ Universidad del Rosario \\ vargasm.maría@urosario.edu.co
}

Recibido: 03/04/14

Aceptado: $22 / 10 / 14$

\section{RESUMEN}

Este es un trabajo investigativo cuyo objetivo fue explorar la modalidad del arteterapia como nueva estrategia de intervención que puede utilizar el fonoaudiólogo en la potenciación y estimulación de aquellas habilidades del lenguaje que se encuentran disminuidas o ausentes. Dicha investigación se realizó en personas con discapacidad intelectual, teniendo en cuenta que generalmente poseen dificultades en la adquisición, desarrollo, consolidación y uso del lenguaje verbal y no verbal, presentando así problemas en el desempeño de actividades escolares, laborales, sociales e incluso en actividades de la vida cotidiana y por supuesto en simbolizar el mundo.

Palabras clave: Fonoaudiólogo, arteterapia, discapacidad intelectual, lenguaje verbal y lenguaje no verbal.

\section{Referencia normalizada}

MOLINA BEJAR R., VARGAS MOSQUERA M. P. (2014). "Arteterapia y fonoaudiología en la potenciación de las habilidades comunicativas en jóvenes con discapacidad intelectual". En Arteterapia: Papeles de arteterapia y educación artística para la inclusión social Vol.: 9. Páginas 113122. Madrid.

\section{SUMARIO}

Introducción. Marco teórico. Objetivo. Metodología. Resultados. Conclusiones. Referencia bibliográfica

\footnotetext{
${ }^{1}$ Fonoaudióloga egresada de la Universidad del Rosario. Magister en Discapacidad e Inclusión Social de la Universidad Nacional. Especialista en docencia universitaria. Fundadora y coordinadora del Programa de apoyo al estudiante con discapacidad, INCLUSER: Profesora - Investigadora Escuela de Medicina y Ciencias de la Salud. Universidad del Rosario

${ }^{2}$ Estudiante del programa de fonoaudiología Escuela de Medicina y Ciencias de la Salud. Universidad del Rosario
} 
Art Therapy and Speech Pathologist Language in The Empowerment of Communication Skills In Young People with Intellectual Disabilities

\begin{abstract}
Researchwork whose aim was to explore the mode of artistic endeavors as a new intervention strategy that can be used in enhancing the speech pathologist language and stimulation of those language skills that are diminished or absent in people with intellectual disabilities. Given that people with this diagnosis have difficulty in the acquisition, development, consolidation and use of verbal and non-verbal language, thus presenting problems in the performance of school, work, social activities and even activities of daily life and symbolize course in the world.
\end{abstract}

Keywords: Speech pathologist language, art therapy, intelectual disabilities, verbal and non-verbal language.

\title{
CONTENTS
}

Introduction. Theoretical framework. Objetive. Methodology. Results. Conclusions. Bibliographic references.

\section{Introducción}

Para que exista la comunicación entre dos o más personas es necesario el lenguaje ya que este funciona como su principal herramienta, la cual implica el manejo de códigos y sistemas de símbolos. Su desarrollo se da desde la gestación hasta los cinco primeros años de vida, en un periodo crítico o ventana de oportunidad en el que ocurre una rápida evolución y adquisición de procesos y habilidades comunicativas fundamentales para el desempeño en el diario vivir y para futuros aprendizajes (Berger, 2007).

Siendo el lenguaje un conjunto de códigos y símbolos, existe una clasificación general que incluye y diferencia el lenguaje verbal del lenguaje no verbal. Las habilidades del lenguaje verbal nos permiten hacer uso de los códigos orales y escritos de una lengua determinada; por otro lado, el lenguaje no verbal se vale de diversos signos que incluyen movimientos corporales, expresiones faciales, imágenes, entre otros. Normalmente durante la comunicación se emplean habilidades, ya sea del lenguaje verbal o del lenguaje no verbal e incluso el uso de ambos de manera simultánea, razón por la que se constituyen como pilares básicos para el desarrollo de una comunicación efectiva.

El estudio del lenguaje ha sido analizado desde diferentes perspectivas y profesiones, entre ellas la fonoaudiología cuyo objeto de estudio es la comunicación humana y sus desórdenes, contribuyendo a la rehabilitación de distintas alteraciones que pueden variar en su grado de afectación; desde leves limitaciones comunicativas hasta discapacidades con mayor impacto en la comunicación presentes en individuos de distintas edades, géneros y/o culturas.

Uno de los diagnósticos que presenta mayor dificultad para establecer un buen desempeño comunicativo es el de discapacidad intelectual, pues altera la adquisi- 
ción, desarrollo, consolidación y uso del lenguaje desde edades tempranas hasta la adultez, impactando la ejecución de actividades escolares, laborales, sociales y del diario vivir. Para dichas dificultades del lenguaje que retardan o interrumpen los nuevos aprendizajes, se han implementado diversas estrategias de intervención que responden a las demandas y necesidades específicas de cada sujeto con discapacidad intelectual. Entre estas estrategias generalmente se encuentra un equipo terapéutico que incluye al fonoaudiólogo, al terapeuta ocupacional yal psicólogo junto con la familia y, dado el caso, a docentes y cuidadores. Sin embargo, es el fonoaudiólogo quien lidera dichas intervenciones para permitir que el joven con discapacidad intelectual haga uso de un lenguaje funcional que responda a las demandas de una comunicación efectiva en diferentes contextos. Es así como estas estrategias de intervención se han orientado al incremento de vocabulario, conductas comunicativas, expresivas espontáneas, uso de señales deícticas y desarrollo de habilidades de comprensión; sin embargo, tales estrategias pueden llegar a ser monótonas, repetitivas y en ocasiones representan altos costos económicos para la familia.

En este sentido, el arteterapia se ha convertido en un buen pretexto para realizar intervenciones en estos sujetos y así incrementar no solamente las habilidades cognitivas, motoras y sensoriales, sino también las habilidades de lenguaje que incluyen la comunicación como base fundamental de futuros aprendizajes. Aunque no hay mucha evidencia sobre el arteterapia en la estimulación y/o potenciación del lenguaje, se sabe que esta herramienta brinda un medio de comunicación no verbal y una alternativa para aquellas personas cuya utilización del lenguaje o su comprensión es parcial o inexistente, pues tal como lo define la Asociación Americana de Arteterapia: "El arteterapia proporciona la oportunidad de expresión y comunicación no verbal, por un lado mediante la implicación para solucionar conflictos emocionales como para fomentar la autoconciencia y desarrollo personal (...)" (Fernández, 2003).

Este proyecto contó con el apoyo del programa OAT (Opciones y Apoyos para la Transición a la vida adulta), cuya misión se basa en ofrecer un programa estructurado como modelo social de inclusión que garantice la participación, el ejercicio ciudadano de los jóvenes con discapacidad intelectual, que les permita desarrollar proyectos de vida adulta plena y productiva. El apoyo de OAT permitió hacer la selección de seis jóvenes con discapacidad intelectual pertenecientes a este programa para realizar el trabajo fonoaudiológico basado en arteterapia.

\section{Marco teórico}

Los conceptos utilizados para esta investigación están directamente relacionados con el ejercicio que se llevó a cabo. Por tanto, para una mayor comprensión de este artículo, tales conceptos serán ampliados a continuación.

\section{Discapacidad Intelectual}

"La discapacidad intelectual se caracteriza por limitaciones significativas tanto en funcionamiento intelectual como en conducta adaptativa tal y como se ha 
manifestado en habilidades adaptativas conceptuales, sociales y prácticas. Esta discapacidad se origina antes de los 18 años" (Definición oficial de discapacidad intelectual de la AAIDD [American Associationon Intellectual and Developmental Disabilities].

El diagnóstico de discapacidad intelectual implica el cumplimiento de tres criterios:

1. Limitaciones significativas en el funcionamiento intelectual: Una puntuación en el coeficiente intelectual (CI) en el que se encuentra aproximadamente dos desviaciones típicas por debajo de la media.

2. Limitaciones significativas en la conducta adaptativa: El desempeño en una medida estandarizada de conducta adaptativa en el que se encuentra aproximadamente dos desviaciones típicas por debajo de la media.

3. Edad de inicio anterior a los 18 años: Edad en la cual comenzó la discapacidad intelectual.

El diagnostico de Discapacidad Intelectual ha de realizarse a partir de información obtenida de instrumentos estandarizados e individualmente administrados que evalúen el funcionamiento intelectual y la conducta adaptativa (AAIDD, 2010).

\section{Lenguaje}

Pese a que el lenguaje es un concepto con diversas definiciones, es indiscutible el hecho de que se manifiesta solo en los seres humanos, siendo una habilidad innata que permite la simbolización del mundo y que se encuentra presente a lo largo de la vida en situaciones cotidianas, puesto que es la principal herramienta de comunicación. Teniendo en cuenta la adquisición y el desarrollo de este, que se evidencia desde los primeros años de vida hasta la vejez, se puede analizar desde sus diferentes dimensiones: forma, contenido y uso, que incluyen los siguientes componentes lingüísticos: pragmático, semántico - sintáctico y fonético-fonológico.

Dentro del contenido del lenguaje se encuentran los aspectos referidos al significado; esto corresponde al nivel semántico que nos permite extraer el significado de las palabras u oraciones y las relaciones que se producen entre estas (Martínez, 1998). Las categorías permiten a los usuarios de una lengua agrupar o clasificar objetos, acciones y relaciones similares para distinguirlos (Owens, 2003). En cuanto a la forma del lenguaje, incluye aquellas reglas relacionadas con la gramática de las palabras y la construcción de las oraciones; esta dimensión abarca 2 niveles del lenguaje: fonético- fonológico y morfosintáctico. El nivel fonético-fonológico hace referencia a las reglas que gobiernan la estructura, la distribución y secuencia de los sonidos del habla (fonemas), y la configuración de las sílabas (Owens, 2003). El nivel morfosintáctico se puede analizar desde el aspecto morfológico, que es la estructura de las palabras y las relaciones que se producen entre estas, y el aspecto de la sintaxis es la estructura de las oraciones 
(Martínez, 1998). Por último, el uso del lenguaje consiste en la selección de comportamientos sociales y cognitivos de acuerdo a las metas del hablante y al contexto de la situación (Martínez, 1998). Esta dimensión del lenguaje incluye el nivel pragmático, que es el uso del lenguaje en la comunicación, y abarca un conjunto de reglas dentro de un contexto (Owens, 2003).

\section{Lenguaje Verbal}

El lenguaje verbal se manifiesta a través de las lenguas; cada lengua posee un conjunto de signos orales y muchas de ellas también sus correspondientes signos escritos, por medio de los cuales se comunican entre sí los miembros de una determinada comunidad. Es decir que el lenguaje verbal posee una doble manifestación, los signos orales y/o palabras habladas y los signos escritos que incluyen los alfabetos, siglas, grafitis, logotipo, ideogramas, jeroglíficos, entre otros.

\section{Lenguaje No Verbal}

El lenguaje no verbal se emplea a través de multitud de signos, que abarca las imágenes sensoriales, los sonidos, los gestos, los movimientos corporales, ente otros. Este lenguaje cumple un papel fundamental durante el acto comunicativo, pues según algunos semiólogos hay mayor cantidad de información no verbal que verbal transmitida y recibida durante tal acto. Adicionalmente, el uso de este contribuye al uso del lenguaje verbal, ampliando o reduciendo el significado del mensaje, dado que lo acompaña, completa, modifica o sustituye.

\section{Arteterapia}

El arte también se usa con fines terapéuticos, pues es una maravillosa herramienta que permite la libre expresión y así mismo la comunicación; esto en su conjunto se define como arteterapia. El arteterapia es, entonces, una herramienta terapéutica que permite abordar a un sujeto a través de las artes plásticas por medio de diferentes técnicas que requieren diversidad de materiales y, de igual modo, representaciones. Se puede usar como un mediador que permite la comunicación y/o exteriorización a través de las diferentes formas artísticas. Cabe resaltar que no es necesaria la experiencia previa en el área artística, pues su objetivo es lograr la expresión o manifestación de sentimientos y/o necesidades a exteriorizar aún cuando estas son inconscientes y de esta forma establecer un vínculo con el entorno.

En el área del lenguaje se puede hacer uso de las artes plásticas para así establecer un medio de comunicación que no necesariamente se base en el lenguaje expresivo oral, pues a través de las diferentes expresiones artísticas se pueden satisfacer las necesidades comunicativas de cada sujeto, teniendo en cuenta las características individuales de su personalidad, gustos, preferencias e incluso desarrollo motor grueso y fino para así adaptar los materiales y escenarios necesarios que favorezcan las producciones de lenguaje no verbal y verbal. 


\section{Objetivo}

Desarrollar una nueva estrategia de intervención basada en arteterapia como herramienta potenciadora de habilidades comunicativas en jóvenes con discapacidad intelectual.

\section{Metodología}

Esta investigación se realizó como un estudio exploratorio- descriptivo ya que se desarrolló dentro de etapas precisas de enunciación del problema, elección de fuentes de selección, de técnicas para recolección de datos y establecimiento de categorías que se adecúan al propósito del estudio y permiten poner en manifiesto relaciones significativas de la información obtenida. Involucró una revisión teórica y búsqueda bibliográfica sobre el arteterapia y su implicación en el uso de este como medio de estimulación y potenciación de las habilidades del lenguaje verbal y no verbal.

Es descriptivo porque caracteriza hechos y situaciones y formas de pensar de individuos en una temática no explorada previamente (Sampieri \& cols, 1991).Además,por cuanto se buscó identificar el campo de acción del fonoaudiólogo en el arteterapia como estrategia de intervención para potenciar las habilidades comunicativas individuales.

Se seleccionaron como instrumentos para recolección la entrevista a informantes clave aplicadas en profesionales de arteterapia. La entrevista consistió en una conversación que el investigador sostuvo con cada uno de los expertos seleccionados, con el objeto de obtener información sobre su perspectiva respecto al arteterapia. (Tabla 1).Los temas fueron pertinentes a su condición y se mantuvo una pauta de entrevista semiestructurada que contenía preguntas generales y específicas. Estas últimas para profundizar en aquellos temas en los cuales el entrevistado tenía información.

Toda esta información recolectada dentro de la búsqueda bibliográfica, el desarrollo del marco teórico y las entrevistas, valió para nutrir el trabajo práctico implementado en los jóvenes seleccionados con discapacidad intelectual del programa OAT. 
Tabla 1

\begin{tabular}{|l|l|l|}
\hline Características & Participante 1 & Participante 2 \\
\hline Género & Femenino & Masculino \\
\hline Profesión de base & Diseño industrial & Maestro de artes plásticas \\
\hline $\begin{array}{l}\text { Lugar de formación } \\
\text { en arteterapia }\end{array}$ & $\begin{array}{l}\text { Academia de bellas artes } \\
\text { de Brera. Milan, Italia. }\end{array}$ & $\begin{array}{l}\text { Máster interuniversitario } \\
\text { en arteterapia y Educa- } \\
\text { ción artística para la } \\
\text { inclusión. Universidades } \\
\text { Complutense, Autónoma } \\
\text { de Madrid y Valladolid. }\end{array}$ \\
\hline $\begin{array}{l}\text { Guía de la temática (preguntas) } \\
\text { ¿Desde cuándo empezó usted a implementar las artes plásticas como medio } \\
\text { terapéutico? } \\
\text { ¿Cuáles son las características iniciales que presentan los sujetos que acuden a } \\
\text { las terapias basadas en artes plásticas? } \\
\text { ¿Considera usted, que esta herramienta sirve como herramienta que favore- } \\
\text { ce/estimula la comunicación y el uso del lenguaje no verbal y verbal? } \\
\text { ¿Qué tipo de materiales y técnicas utiliza usted en sus sesiones? } \\
\text { ¿Cómo adecúa usted los materiales y las técnicas para cada sujeto? } \\
\text { ¿De todas las expresiones artísticas que usted utiliza en sus terapias, cuál es la } \\
\text { que más recomienda y por qué? }\end{array}$ \\
\hline
\end{tabular}

\section{Selección de jóvenes con discapacidad intelectual}

Se procedió a 1) la selección de jóvenes con discapacidad intelectual, iniciando con observaciones estructuradas en el aula y en otros espacios que permitieran dar cuenta de las habilidades comunicativas de estos sujetos. Una vez se identificaron las habilidades en el uso del lenguaje verbal y no verbal con pares y docentes, se llevó a cabo la selección de seis (6) jóvenes con una diferencia notable en el desempeño comunicativo, debido al poco uso del lenguaje o incluso ausencia de este en cualquiera de sus modalidades (verbal- no verbal).

Una vez seleccionados, 2) se dividió la población en dos grupos, de tal manera que cada grupo compartiera las mismas necesidades comunicativas; uno de ellos con mayores alteraciones a nivel expresivo oral y otro de estos con dificultades leves en la misma área.

Por último 3) se inició el trabajo fonoaudiológico basado en arteterapia, fundado en un solo eje temático que fue el "trabajo". A partir de este se desarrollaron subtemas relacionados con el tema central de manera directa e indirecta, que fueron de apoyo para permitir que los jóvenes interiorizaran dicha información y que la pudieran poner en práctica en actividades cotidianas, tal como se muestra en la tabla 2. 
Tabla 2.

\begin{tabular}{|l|l|}
\hline Tema & Subtema \\
\hline \multirow{4}{*}{ Trabajo } & ¿Qué es el trabajo? Tipos de trabajo \\
\cline { 2 - 2 } & Higiene y presentación personal \\
\cline { 2 - 2 } & Redes sociales \\
\cline { 2 - 2 } & Sentimientos \\
\cline { 2 - 2 } & Tiempo libre \\
\hline
\end{tabular}

\section{Resultados}

Teniendo en cuenta los diferentes momentos para el desarrollo de este estudio, los resultados obtenidos permiten dar cuenta de que:

- La revisión bibliográfica no arrojó resultados suficientes para documentar el arteterapia como herramienta de estimulación del lenguaje. En el análisis de seis artículos encontrados en revistas y libros, la información sobre arteterapia se relacionaba con la cognición y algunos desarrollos en el ser humano. Además, se referían al trabajo psicológico y psiquiátrico, razón por la cual se hace necesario seguir explorando, indagando y documentando las diversas funciones que cumple el arteterapia como herramienta terapéutica en aspectos lingüísticos

Los informantes clave, profesionales en arteterapia, se refirieron a esta como una terapia que permite el trabajo con diferentes tipos de personas, aunque su interés principal se ha enfocado en población con alguna discapacidad; manifiestan que el arteterapia les ofrece un amplio rango de posibilidades para la expresión y que en ocasiones por su condición de salud no pueden expresarse de manera verbal, por lo que encuentran que este tipo de intervención favorece todo tipo de expresión por medio de símbolos, metáforas e incluso con la exploración de texturas, colores, aromas, intensidades, tiempos e imágenes en los que la variedad de elementos les confiere su versatilidad y utilidad. Además el arteterapia le brinda a un individuo la oportunidad de exteriorizar no solo su vida real o la problemática a la que se enfrenta, sino que es un medio para que emerjan aquellas emociones y sensaciones que están ancladas en su interior y muchas veces en su inconsciente, de las que los mismos sujetos se han sorprendido.

“...el arteterapia está dirigida al trabajo con diferentes poblaciones y rangos de edad. En mi caso particular mi principal interés se centra en la discapacidad...".

“...además mediante la expresión artística afloran muchos contenidos del subconsciente, que hasta la misma persona se sorprende...".

"...la obra sirve como un canal o intermediario entre la vivencia interior de la persona y su entorno...".

- El trabajo fonoaudiológico basado en arteterapia permitió dar cuenta de la importancia y la funcionalidad de esta como herramienta que estimula todas las habilidades comunicativas, que abarcan las diferentes dimensiones del lenguaje. Dentro de la dimensión morfosintáctica, los jóvenes estructuraron mejor su lenguaje expresivo. En la dimensión semántica se observó mayor compren- 
sión y expresión de un amplio vocabulario. Por último en la dimensión pragmática, hubo mayor fluidez y apropiación en el discurso oral. Además, en el transcurso de la intervención terapéutica los jóvenes manifestaron afinidad con el arte y la confianza que brindan estas prácticas para exteriorizar los conocimientos y experiencias propias, afianzando un tema específico, en este caso el "ingreso al trabajo". Lo aprendido se convirtió en comprender las posibilidades y oportunidades de acceder a un empleo y transitar a la vida adulta.

- Teniendo en cuenta los resultados y el impacto de las arteterapias en la potenciación de las habilidades comunicativas, se debe tener presente que aun cuando la intervención sea grupal es mejor trabajar con grupos no superiores a cinco (5) personas, con el fin de mejorar la interacción con cada uno de ellos, brindando un espacio en el que todos puedan participar activamente y desempeñarse de manera natural, sin ignorar factores externos vitales como la ambientación y el espacio para desarrollar este tipo de intervención, pues el desempeño y actitud de los sujetos está mediado por dichos factores.

\section{Conclusiones}

El arte es la manifestación de la actividad humana mediante la cual se expresa una visión personal y desinteresada que interpreta lo real o imaginario con recursos plásticos, lingüísticos o sonoros (Real Academia Española). Es así como el arte se ha utilizado con fines terapéuticos, considerado como un espacio de expresividad y creatividad. Es una estrategia de intervención terapéutica auto expresiva en personas de diferentes edades, condiciones y diagnósticos de base. El arte actúa como una forma de comunicación simbólica o gráfica inmediata dirigida hacía alguien más o hacia el mismo sujeto como expresión de emociones, ideas, sueños, frustraciones, etc. Este tipo de terapia con forma de juego contribuye a la expresión espontánea, que permite exteriorizar todo aquello que se desea comunicar (Schaefer y O'Connor, 1988).

Los diferentes autores analizados y los profesionales en arteterapia como informantes clave, confirman que el arteterapia es un puente para la expresión humana y la comunicación que le permiten al sujeto reflejar su esencia, su interior e incluso brindar la oportunidad de conocerse así mismo. Es clara la necesidad que posee todo ser humano de encontrar otro tipo de lenguajes para manifestar y exteriorizar elementos y sentimientos que por ausencia o disminución de la expresión oral o en ocasiones por temor de algunos prejuicios sociales no se declaran. Dentro del trabajo fonoaudiológico basado en arteterapia con los jóvenes de discapacidad se pudo observar que estas personas utilizaron la representación gráfica como lenguaje no verbal para articular elementos que no se encontraron presentes dentro de su discurso oral.

El arteterapia demostró ser una excelente estrategia de intervención que permite afianzar elementos del lenguaje expresivo, junto con la exploración de diversas sensaciones que condescienden en el desarrollo de la creatividad y con esto dan paso a nuevas y propias creaciones que surgen de la experiencia individual. Por ello es clara la necesidad de iniciar desde edades tempranas con el fin 
de brindar una terapia integral que abarque el lenguaje en su totalidad, puesto que en edades avanzadas esto puede llevar más tiempo y se desviara del objetivo de la intervención fonoaudiológica basada en arteterapia. Así mismo, es necesario generar todo un plan de trabajo que permita tener mayor continuidad, y de esta manera impactar significativamente el lenguaje y las habilidades pertenecientes a este, como base de la comunicación y de futuros aprendizajes.

\section{Referencias bibliográficas}

ÁlVAREZ, J. (1995). Psicología de la educación. Barcelona: Editorial Boixareu Universitaria.

Asociación Americana de Discapacidades Intelectuales y del Desarrollo AAIDD. (2010). Discapacidad Intelectual. Definición, clasificación y sistemas de apoyo. Madrid: Alianza Editorial.

BERGER, K. (2007). Psicología del desarrollo. Infancia y adolescencia. Madrid: Editorial Médica Panamericana.

COLL, F Y BARRGAN, M. (2006). Arteterapia. Dinámicas entre creación y procesos terapéuticos. España: Universidad de Murcia. Servicio de publicaciones

FERNÁNDEZ, M. (2003). Creatividad, arteterapia y autismo. Un acercamiento a la actividad plástica como proceso creativo en niños autistas. Rev. Art. Ind. Soci, 15: 135-152.

LOWENFEL, V. (1997). El niño y su arte. Buenos Aires: Editorial Kapelusz.

MARTÍNEZ CELDRAN, E. (2002) Logopedia. Lingüística. Teoría y aplicaciones. Barcelona: Editorial Masson.

MARTÍNEZ, E. (1998). Lingüistica, teoría y aplicaciones. Barcelona; Editorial Masson

OWENS, R. (2003). Desarrollo del lenguaje. 5 edición. Madrid: Editorial Pearson

SAMPIERI, R, FERNÁNDEZ,C.\& BAPTISTA, P (1991).Metodología de la investigación. México.

SCHAEFER, C Y O'CONNOR K. (1988). Manual de terapia de juego. México D.F: Editorial el manual moderno S.A de C.V. 